\title{
Predicting the cumulative effect of multiple disturbances on seagrass connectivity
}

\author{
Alana Grech $^{1,2}$ (D) | Emmanuel Hanert ${ }^{3}$ | Len McKenzie ${ }^{4}$ | Michael Rasheed ${ }^{4}$ | \\ Christopher Thomas $^{5}$ | Samantha Tol ${ }^{4}$ | Mingzhu Wang ${ }^{2}$ | Michelle Waycott ${ }^{6}$ | \\ Jolan Wolter ${ }^{3}$ | Rob Coles ${ }^{4}$
}

${ }^{1}$ ARC Centre of Excellence for Coral Reef Studies, James Cook University, Townsville, QLD, Australia

${ }^{2}$ Department of Environmental Sciences, Macquarie University, Sydney, NSW, Australia

${ }^{3}$ Earth and Life Institute (ELI), Université catholique de Louvain, Louvain-la-Neuve, Belgium

${ }^{4}$ TropWATER (Centre for Tropical Water \& Aquatic Ecosystem Research), James Cook University, Cairns, QLD, Australia

${ }^{5}$ Institute of Mechanics, Materials and Civil Engineering, Université catholique de Louvain, Louvain-la-Neuve, Belgium

${ }^{6}$ School of Biological Sciences, Environment Institute, Australian Centre for Evolutionary Biology and Biodiversity, The University of Adelaide, Adelaide, SA, Australia

\section{Correspondence}

Alana Grech, ARC Centre of Excellence for Coral Reef Studies, James Cook University, Townsville, QLD, Australia.

Email: alana.grech@jcu.edu.au

\section{Funding information}

Macquarie University; James Cook University; Australian Research Council Centre of Excellence for Coral Reef Studies; lan Potter Foundation; Sea World Research and Rescue Foundation Inc, Grant/Award Number: SWR/6/15; Wallonie-Bruxelles International

\begin{abstract}
The rate of exchange, or connectivity, among populations effects their ability to recover after disturbance events. However, there is limited information on the extent to which populations are connected or how multiple disturbances affect connectivity, especially in coastal and marine ecosystems. We used network analysis and the outputs of a biophysical model to measure potential functional connectivity and predict the impact of multiple disturbances on seagrasses in the central Great Barrier Reef World Heritage Area (GBRWHA), Australia. The seagrass networks were densely connected, indicating that seagrasses are resilient to the random loss of meadows. Our analysis identified discrete meadows that are important sources of seagrass propagules and that serve as stepping stones connecting various different parts of the network. Several of these meadows were close to urban areas or ports and likely to be at risk from coastal development. Deep water meadows were highly connected to coastal meadows and may function as a refuge, but only for non-foundation species. We evaluated changes to the structure and functioning of the seagrass networks when one or more discrete meadows were removed due to multiple disturbance events. The scale of disturbance required to disconnect the seagrass networks into two or more components was on average $>245 \mathrm{~km}$, about half the length of the metapopulation. The densely connected seagrass meadows of the central GBRWHA are not limited by the supply of propagules; therefore, management should focus on improving environmental conditions that support natural seagrass recruitment and recovery processes. Our study provides a new framework for assessing the impact of global change on the connectivity and persistence of coastal and marine ecosystems. Without this knowledge, management actions, including coastal restoration, may prove unnecessary and be unsuccessful.
\end{abstract}

KEYWORDS

connectivity, cumulative effects, graph theory, Great Barrier Reef, networks, seagrass

\section{1 | INTRODUCTION}

The rate of exchange, or connectivity, among populations affects population and metapopulation dynamics and genetics (Cowen \&
Sponaugle, 2009; McMahon et al., 2014), responses to species invasions and disease transmission, species expansion and the replenishment of populations after disturbance events (Treml, Halpin, Urban, \& Pratson, 2008). For example, well-connected coral reefs receive a 
high number of larvae from multiple source reefs and recover more rapidly from disturbances such as bleaching and storms (Hughes, Bellwood, Folke, Steneck, \& Wilson, 2005; Thomas, Bridge, Figueiredo, Deleersnijder, \& Hanert, 2015). Identifying and protecting pathways of connectivity are critical to effective conservation outcomes because they support population persistence, ecosystem function and biological diversity (Steneck et al., 2009). However, connectivity estimates are rarely incorporated into conservation decision-making because of a lack of quantitative data on dispersal pathways and the spatial scale and extent to which populations are connected (Almany et al., 2009; Magris, Pressey, Weeks, \& Ban, 2014). Measuring dispersal and connectivity is particularly difficult in marine ecosystems because of the challenges associated with tracking propagules, individuals and larvae (D'Aloia et al., 2015) over broad spatial scales and in a dynamic three-dimensional fluid environment (Saunders et al., 2016).

Studies that empirically measure dispersal and connectivity in marine ecosystems use techniques such as electronic tagging (Block et al., 2011), capture-mark-recapture (Lowe \& Allendorf, 2010), larval tagging (Almany, Berumen, Thorrold, Planes, \& Jones, 2007), and genetic approaches, such as DNA parentage analysis (e.g. Almany et al., 2013; Harrison et al., 2012; Planes, Jones, \& Thorrold, 2009). However, empirical measures of connectivity are limited to a few marine species due to cost and logistical constraints (Abesamis, Stockwell, Bernardo, Villanoy, \& Russ, 2016; Kool, Moilanen, \& Treml, 2013) and relatively small spatial and temporal scales (Andrello et al., 2013). An alternative approach is the coupling of species dispersal parameters with hydrodynamic parameters in biophysical models (e.g. Abesamis et al., 2016; Cowen, Paris, \& Srinivasan, 2006; Grech et al., 2016; Thomas et al., 2014; Treml \& Halpin, 2012). Biophysical models predict the movement of individuals by tracking particles using numerical models to describe the motion of waters, and biological parameters to define the attributes of a species, including larval and propagule duration and mortality, timing of release and behaviour in the water column. Outputs of biophysical models can be used to populate matrices with the number of "virtual" individuals moving among locations, enabling the exploration and analysis of connectivity using techniques such as graph theory (Treml et al., 2008).

The application of graph (or network) theory to landscape ecology and conservation biology is rapidly growing, particularly in connectivity and metapopulation analysis (Urban, Minor, Treml, \& Schick, 2009). Graph theory provides a flexible framework for visualising and characterising connectivity at multiple spatial scales by representing how habitats and subpopulations are physically or logically linked (Rayfield, Fortin, \& Fall, 2011). In weighted graphs (or networks), nodes represent discrete habitat patches or subpopulations, and edges (or links) between nodes indicate the direction and relative strength of dispersal and the resultant functional connections. Graph theory enables the assessment of the emergent properties and key structural characteristics of large and complex networks (Kool et al., 2013). For example, measures of centrality (e.g. betweeness, degree and closeness) indicate the role of a node relative to its neighbours or the entire network (Estrada \& Bodin, 2008). These measures are important for identifying habitats or subpopulations that exert a high degree of influence over the entire network or metapopulation. Graph theory also enables the assessment of the impact of disturbance events on connectivity, a task that is notoriously complex and difficult to measure (Gonzalez, Rayfield, \& Lindo, 2011). Removing nodes or edges from a graph indicates the potential of a metapopulation to withstand the loss of discrete habitats or subpopulations (Cumming, Bodin, Ernstson, \& Elmqvist, 2010) and provides a measure of a metapopulation's robustness to disturbance events (Saunders et al., 2016; Urban \& Keitt, 2001).

Tropical seagrasses are regularly exposed to multiple disturbance events, both natural (e.g. storms, cyclones and high rainfall) and human-induced (e.g. coastal development, sediment loads from land use, dredging and shipping; Grech et al., 2012). It is typical that studies on seagrass recruitment and recovery following disturbance events focus on clonal reproduction (e.g. Kendrick et al., 2017). Sexual reproduction is also an essential mechanism for recruitment and recovery, but its contribution to the persistence and maintenance of seagrass populations is less understood (Kendrick et al., 2012). Studies examining both sexual and asexual reproduction have found that while some seagrass populations rely largely on clonal growth for population maintenance (Rasheed, 1999, 2004), in the case of large scale meadow loss (Rasheed, McKenna, Carter, \& Coles, 2014), or for annual or ephemeral populations (Hovey et al., 2015; York et al., 2015), sexual reproduction is of critical importance. Seagrass fruits and propagules of most species are capable of dispersing long distances via the convective forces of ocean waves and currents (Kendrick et al., 2017; McMahon et al., 2014). Long distance dispersal supports meadow connectivity and the natural recolonisation of sites after disturbance events (Kendrick et al., 2017); however, very few studies have attempted to quantify seagrass dispersal and connectivity at broad spatial scales (Jahnke et al., 2017; Ruiz-Montoya, Lowe, \& Kendrick, 2015). Tropical seagrasses occur in some of the world's most threatened coastal regions (Orth et al., 2006; Waycott et al., 2009), and there is a critical need to assess the role of connectivity in seagrass replenishment and recovery after disturbance events, the effect of disturbance events on seagrass connectivity and its implications for the conservation of coastal habitats (York et al., 2017).

The goal of our study was to assess seagrass connectivity and quantify the cumulative impact of multiple disturbance events in the central Great Barrier Reef World Heritage Area (GBRWHA), Queensland, Australia. Potential functional connectivity was measured using the outputs of a biophysical model of seagrass dispersal and settlement and network analysis. Network analysis was used to evaluate changes to the structure and functioning of the seagrass networks when one or more discrete meadows were removed due to multiple disturbance events. We used the outputs of our analysis to evaluate seagrass meadow connectivity in the central GBRWHA, predict the impact of disturbance events on connectivity and to identify strategies that support the replenishment and recovery of seagrass meadows following disturbance events. 


\section{MATERIALS AND METHODS}

\section{1 | Study area}

The GBRWHA covers an area of $348,000 \mathrm{~km}^{2}$ (Figure 1) and was inscribed on the World Heritage List in 1981 for its superlative natural beauty, ecological diversity and relative intactness. The Australian Government has international responsibilities under the World Heritage Convention to conserve the region, including its seagrass habitats. The $40,000 \mathrm{~km}^{2}$ of tropical seagrass habitats of the GBRWHA region are characterised by low nutrient availability and high diversity, disturbance and productivity (Coles et al., 2015; Waycott et al., 2009) and are spatially and temporally dynamic (ephemeral). The 15 GBRWHA seagrass species are a vital component of the reef ecosystem and provide food for numerous fish, crustacean, sea turtles and dugong (Unsworth, van Keulen, \& Coles, 2014). We assessed potential functional connectivity among seagrass meadows using the central GBRWHA as an example (Figure 1). This area includes $\sim 6,000 \mathrm{~km}^{2}$ of seagrass habitats and was chosen because: (1) there are $>30$ years of seagrass data and biophysical models available; (2) there is published evidence of seagrass loss and recovery in the region (e.g. Rasheed et al., 2014); and (3) the central GBRWHA has been exposed to a variety of disturbance events, including cyclones (e.g. Category 5 Yasi, Category 4 Hamish and Category 4 Debbie), high rainfall events causing turbid flood plumes, urban and industrial development (e.g. Townsville) and port developments (e.g. Townsville and Abbot Point; Figure 1).

\section{2 | Seagrass dispersal and connectivity modelling}

We created connectivity matrices for seagrass meadows in the central GBRWHA using the biophysical model outputs of Grech et al. (2016). Grech et al. (2016) delineated the spatial extent of seagrass meadows with a spatial (geographic information system [GIS]) layer of intertidal, shallow subtidal and deep water seagrass distribution, derived from McKenzie, Yoshida, Grech, and Coles (2014) and Coles,
FIGURE 1 (a) Distribution of foundation (Halodule, Cymodocea and Zostera species) and non-foundation (Halophila species) seagrass meadows in the central Great Barrier Reef World Heritage Area; (b) the location of the central Great Barrier Reef World Heritage Area study area on the north-east coast of Australia (QLD, Queensland); and, (c) the location of the study area in the Great Barrier Reef World Heritage Area [Colour figure can be viewed at wileyonlinelibrary.com]

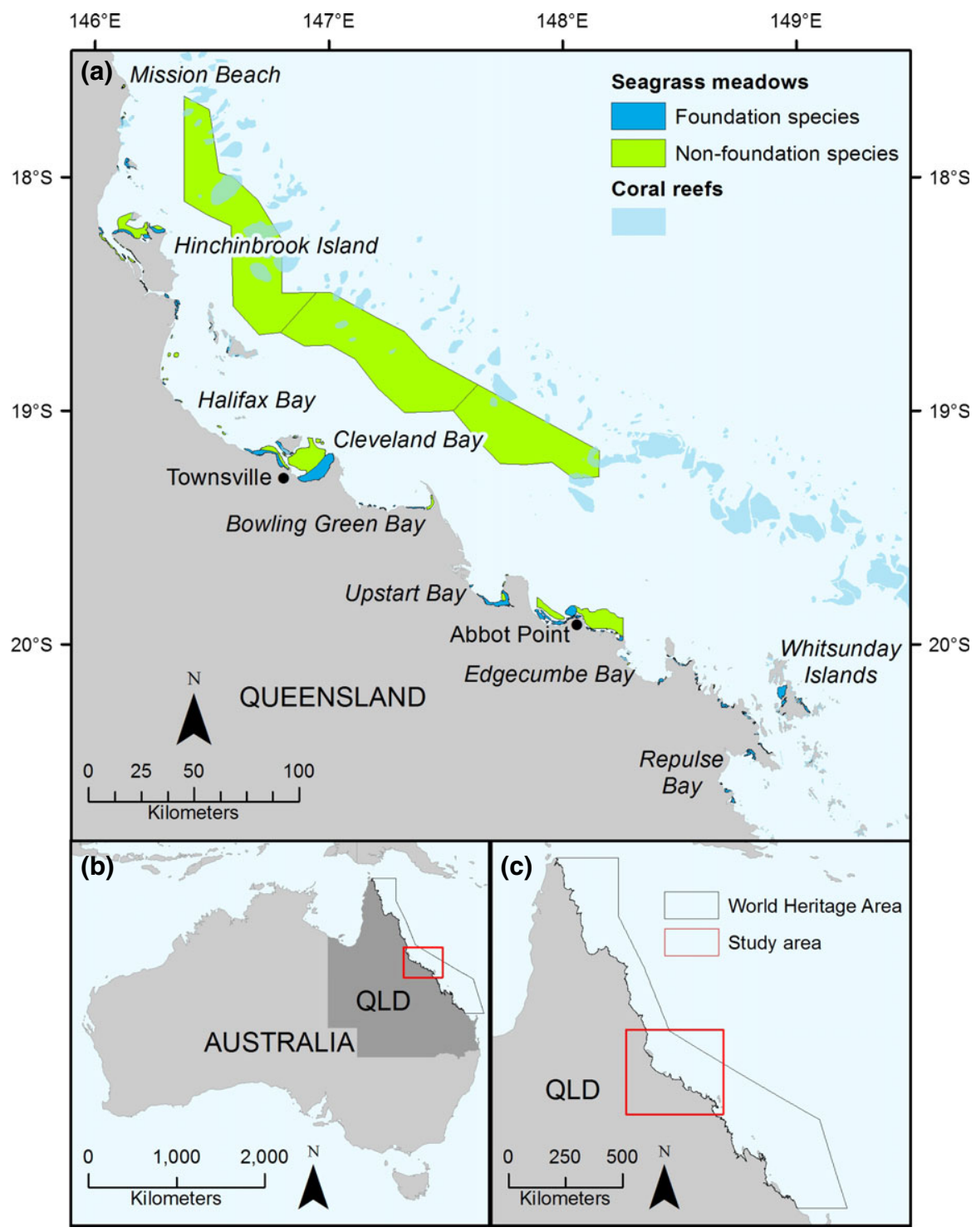


McKenzie, De'ath, Roelofs, and Lee Long (2009) (Figure 1). They modelled the hydrodynamics of the central GBRWHA using the depth-integrated finite element Second-generation Louvain-la-Neuve Ice-ocean Model (SLIM; Lambrechts et al., 2008). Biological parameters were incorporated in SLIM to simulate the dispersal and settlement patterns of "virtual" propagules (i.e. plant fragment, fruit or spathe) to and from known sites of seagrass presence. These parameters included: (1) simulating the dispersal of "virtual" propagules floating at the surface (affected by wind speed and direction) and suspended below the surface; (2) a first-order decay function to simulate the gradual settlement of particles; and (3) 68 simulations ran for a maximum of 8 weeks during the peak of the flowering period (from 1 August 2012 to 31 January 2013), capturing variability in winds, tides and currents.

The total area of seagrass included in the Grech et al. (2016) analysis was $6,710.2 \mathrm{~km}^{2}$ (intertidal and shallow subtidal $=857.5 \mathrm{~km}^{2}$; deep $=5,852.7 \mathrm{~km}^{2}$ ), comprised of 100 discrete meadows (intertidal and subtidal $=97$; deep $=3$; Table S1). The size of intertidal and shallow subtidal seagrass meadows ranged from 0.41 to $157.1 \mathrm{~km}^{2}$ (mean $=8.8 \mathrm{~km}^{2}$ ) and deep water 1,417.3-2,335.0 km (mean $=1,950.9 \mathrm{~km}^{2}$; Table S1). To facilitate connectivity analysis, individual seagrass meadows were allocated into one of two generalised species classes based on similar life-history traits (Figure 1; Kilminster et al., 2015): the structurally more robust, competitively dominant and persistent tropical seagrass species (genera Halodule, Cymodocea and Zostera; $n=67$ ), referred to as foundation species, and the structurally small, ephemeral and transient species of the genus Halophila $(n=33$ ), referred to as non-foundation species.

Grech et al. (2016) utilised a model which spread the particle release locations evenly across intertidal and shallow subtidal meadows at intervals of $\sim 2 \mathrm{~km}$, and an equal number of particles (representing "virtual" seagrass propagules) were released per location. Release locations were spread evenly across each deep water meadow at intervals of $\sim 10 \mathrm{~km}$. The number of particles released per unit area was smaller in deep water meadows than in intertidal and shallow subtidal meadows because deep water seagrasses have lower biomass and abundance relative to coastal seagrass (Coles et al., 2007, 2009; Rasheed et al., 2014).

We calculated the cumulative "virtual" propagule settlement from the 68 simulations of Grech et al. (2016) within foundation and nonfoundation meadows in GIS. The outputs were used to populate weighted and directed connectivity matrices of the number of "virtual" propagules from every seagrass meadow $i$ to every other meadow $j$.

\section{3 | Connectivity measures}

We used the foundation and non-foundation seagrass connectivity matrices and network analysis to explore spatial patterns of connectivity, identify potential dispersal pathways and locate critical source meadows in the central GBRWHA. In our study, networks (referred to as habitat graphs) are a set of nodes that represent discrete seagrass meadows (McKenzie et al., 2014) and edges (or links) between nodes indicate functional connections. Edges are weighted by the number of "virtual" propagules from every seagrass meadow $i$ to every other meadow $j$.

We used the GIS software ArcGIS 10.2 (https://www.arcgis.com) and the network analysis software Gephi 0.9.2 (https://gephi.org) to quantify connectivity of the foundation and non-foundation habitat graphs. At a network scale, we used a range of measures to define the two habitat graphs (Table 1) and node degree distribution (probability distributions of node degrees over the entire network) to assess communicability within the network (Kool et al., 2013; Minor \& Urban, 2008). At an element (node) scale, we used: betweenness centrality to identify meadows that serve as stepping stones connecting various different parts of the habitat graph (Estrada \& Bodin, 2008; Treml \& Halpin, 2012); outflux (or weighted out-degree) to identify important source meadows (Magris, Treml, Pressey, \& Weeks, 2015); PageRank to identify important source meadows that takes into account the full topology of the habitat graph (Allesina \& Pascual, 2009) and local retention to identify the relative amount of meadow self-replenishment (Treml \& Halpin, 2012). We used modularity and the Louvain algorithm (Blondel, Guillaume, Lambiotte, \& Lefebvre, 2008) to detect communities (or clusters) of nodes that are densely connected to each other and weakly connected to other nodes in the network (Thomas et al., 2014). A sensitivity analysis was used to identify a resolution with a modularity value $>0.4$, indicating that the graph had a prominent community structure.

Large meadows released a higher number of "virtual" propagules in the 68 simulations of Grech et al. (2016) relative to smaller meadows because they had more particle release locations (see Seagrass dispersal and connectivity modelling). We assessed the influence of meadow size on the habitat graphs by comparing outflux with meadow area to identify nodes that contributed a high number of propagules to the network relative to their size.

We compared the foundation and non-foundation habitat graphs with a random network to assess their network type. We generated random networks using the Erdős-Rényi model in the $\mathrm{R}$ package igraph (Csardi \& Nepusz, 2006). The Erdős-Rényi model uses the same number of nodes and edges of a real graph to generate a random network. The difference between the real and random graphs is that the edges in the random graph are randomly distributed between nodes. A total of 1,000 random networks were created using the same number of nodes and edges of the foundation and non-foundation graphs. We used Wilcoxon's signed-rank tests to determine whether the network metrics of the random graphs were significantly different to the network metrics of the foundation and non-foundation habitat graphs.

\subsection{Cumulative impact assessment}

We assessed the cumulative effect of multiple impacts on the connectivity of foundation and non-foundation meadows by sequentially removing nodes (meadows) similar in spatial location to six real-world events (Table 2; Figure S1): Severe Tropical Cyclone Yasi; Severe Tropical Cyclone Hamish; Severe Tropical Cyclone Debbie; the Port of 
TABLE 1 Network measures of the foundation and non-foundation habitat graphs

\begin{tabular}{|c|c|c|c|}
\hline Network measure & Description (Rayfield et al., 2011) & $\begin{array}{l}\text { Foundation } \\
\text { species }\end{array}$ & $\begin{array}{l}\text { Non-foundation } \\
\text { species }\end{array}$ \\
\hline Network order & Total number of nodes & 67 & 33 \\
\hline Average degree & $\begin{array}{l}\text { Mean of the number of edges per node. Indicates the } \\
\text { average accessibility of each node }\end{array}$ & 42.0 & 29.5 \\
\hline Connectance (network density) & $\begin{array}{l}\text { Measures how close the network is to complete. A complete } \\
\text { graph has all possible edges and density equal to } 1\end{array}$ & 0.32 & 0.46 \\
\hline Average clustering coefficient & $\begin{array}{l}\text { Average of the clustering coefficient of nodes. Clustering coefficient } \\
\text { indicates the degree to which a node's neighbourhood is a complete graph }\end{array}$ & 0.48 & 0.57 \\
\hline Average path length & The average number of steps it takes to reach any other node in the network & 2.57 & 1.71 \\
\hline $\begin{array}{l}\text { Number of connected } \\
\text { components }\end{array}$ & $\begin{array}{l}\text { Number of connected subgraphs (components). Components } \\
\text { are sets of nodes connected to each other }\end{array}$ & 1 & 1 \\
\hline $\begin{array}{l}\text { Number of communities } \\
\text { (modularity) }\end{array}$ & $\begin{array}{l}\text { Number of clusters measured by the strength of division of the } \\
\text { network into groups (or communities) compared to a random network }\end{array}$ & 6 & 4 \\
\hline
\end{tabular}

Abbot Point development; the regional city (population $\sim 172,000$ ) and Port of Townsville; and flooding of the Burdekin River. We assumed that all meadows immediately adjacent to Abbot Point, Townsville and the Burdekin River were completely destroyed, and all meadows exposed to the very destructive winds of Cyclone Yasi, Hamish and Debbie were completely destroyed. We used a Bray-Curtis dissimilarity matrix and three network measures to assess the relative impact of all possible combinations of disturbance events $(n=63)$ on the connectivity of foundation and non-foundation habitat graphs: network diameter (or traversibility; maximum number of connections required to traverse the network; Minor \& Urban, 2008; Moore, Grewar, \& Cumming, 2016); network density (or connectance; measures how close the network is to complete; Moore et al., 2016); and average clustering coefficient (average of the clustering coefficient of nodes in the network; Minor \& Urban, 2008).

We assessed the spatial scale of disturbance required to disconnect the habitat graphs into two or more components by sequentially removing nodes (meadows) from the foundation and non-foundation habitat graphs. The nearest node of every focal meadow $(n=100)$ was removed until the habitat graph was disconnected. We then measured the Euclidian distance between the focal meadow and its furthest cut-node. A cut-node is a single node that causes a network to be disconnected into two or more components when it is removed (Urban \& Keitt, 2001).

\section{RESULTS}

The foundation species habitat graph was comprised of 67 nodes and 1,406 edges (Figures 2 and S2, Tables 1 and S1) and the non-foundation graph 33 nodes and 487 edges (Figures 2 and S3, Tables 1 and S1). Both graphs were densely connected and featured only one component. Both graphs also exhibited the properties of a small-world network: highly clustered (Table 1), no hubs (i.e. nodes with a high number of edges relative to other nodes; Figure S4) and short average path length and graph diameter relative to network order (Table 1). In small-world networks, connectivity is resilient to the random loss of nodes as there are many redundant connections (Minor \& Urban, 2007, 2008).

There was no significant difference in the network diameter, number of components and average path length between the non-foundation habitat graph and the random network of the same number of nodes and edges. However, the foundation habitat graph was less connected than what occurs randomly; the network diameter and average path length were significantly lower $(p<.001)$ in the random network; however, the number of components was the same (1).

The "virtual" propagules released from high outflux node 40 primarily remained within Upstart Bay, resulting in a high level of local retention (97\%; Figures 3 and 4, Table S1). Other meadows of high (>90\%) local retention were also located in Upstart Bay (non-foundation node 94) and near Hinchinbrook Island (foundation nodes 82 , 83, 88 and 96, non-foundation nodes 80 and 84), in Repulse Bay (foundation node 5) and around the Whitsunday Islands (foundation nodes 7 and 9; Figures 3 and 4, Table S1). Meadows with high local retention are more likely to be self-persistent (Burgess et al., 2014), but are also vulnerable to disturbance events as they are less connected to other meadows in the network and therefore less likely to be replenished.

We removed local retention from node outflux to provide a measure of the relative importance of meadows as a source of 
TABLE 2 Foundation and non-foundation meadows (nodes) that overlapped or were adjacent to six disturbance events (Figure S1) in the central Great Barrier Reef World Heritage Area

\begin{tabular}{|c|c|c|c|c|}
\hline Disturbance event & Disturbance type & $\begin{array}{l}\text { Region effected by } \\
\text { disturbance }\end{array}$ & Foundation nodes & Non-foundation nodes \\
\hline $\begin{array}{l}\text { Severe Tropical Cyclone } \\
\text { Yasi (2-4 February 2011) }\end{array}$ & Climatic & $\begin{array}{l}\text { South Hinchinbrook } \\
\text { Island-Mission Beach }\end{array}$ & $\begin{array}{l}72,73,74,75,78,81,82,83 \\
85,86,87,88,96\end{array}$ & $\begin{array}{c}76,77,79,80,84 \\
89,90,91,97\end{array}$ \\
\hline $\begin{array}{l}\text { Severe Tropical Cyclone } \\
\text { Hamish (4-16 March 2009) }\end{array}$ & Climatic & Deep water & - & $98,99,100$ \\
\hline $\begin{array}{l}\text { Severe Tropical Cyclone } \\
\text { Debbie (26-28 March 2017) }\end{array}$ & Climatic & $\begin{array}{l}\text { Whitsunday Islands and } \\
\text { Repulse Bay }\end{array}$ & $\begin{array}{c}1,2,3,4,5,6,7,8,9,10,11 \\
12,13,14,15,16,17,18,19,20 \\
21,23,24,26,27,29,30,31\end{array}$ & $22,25,28$ \\
\hline Port of Abbot Point & Coastal development & $\begin{array}{l}\text { Abbot Point and } \\
\text { Abbot Bay }\end{array}$ & 36,95 & 38 \\
\hline $\begin{array}{l}\text { Regional city and } \\
\text { Port of Townsville }\end{array}$ & Coastal development & Cleveland Bay & $52,54,92$ & $51,53,93$ \\
\hline
\end{tabular}

Nodes, representing meadows (see Figure 4 for ID), were sequentially removed from the foundation and non-foundation habitat graphs to assess the relative impact of all possible combinations of disturbance events $(n=63)$ on the connectivity of the foundation and non-foundation habitat graphs.

propagules (Figure 3, Table S1). Meadows of high outflux minus local retention were located in Cleveland Bay (foundation nodes 52 and 92, non-foundation node 53), deep water (non-foundation nodes 98, 99 and 100), Abbot Point (foundation nodes 35 and 36, non-foundation node 38 ) and around the Whitsunday Islands (foundation nodes 6, 8 and 21; Figures 3 and 4, Table S1). High outflux foundation nodes 52 and 92 and non-foundation nodes 53 and 99 in Cleveland Bay and deep water also had high PageRanks values, further supporting their relative importance as source meadows in the region (Table S1).

We used the measure of outflux minus local retention (Figure 3) to assess the influence of meadow size on a nodes contribution to "virtual" propagules. Large foundation meadows exported greater numbers of "virtual" propagules than smaller meadows (Table S1), and there was a positive and significant correlation $(r(66)=.86$, $p<.001$ ) between meadow area and meadow outflux (Figure S5). Large non-foundation meadows also exported a high number of "virtual" seagrass propagules, and there was a positive and significant correlation $(r(32)=.87, p<.001)$ between meadow area and meadow outflux (Figure S5). The three large non-foundation deep water meadows (nodes 98, 99 and 100; Figure 4) had a disproportionately low outflux relative to their size because the density of particle release locations was smaller and many "virtual" propagules dispersed in a north-east direction (Grech et al., 2016). Meadows that contributed a high number of "virtual" propagules relative to their size were located in Cleveland Bay (foundation nodes 52 and 92, non-foundation nodes 53), deep water (non-foundation nodes 98, 99 and 100), the Whitsunday Islands (foundation node 21) and Abbot Point (foundation node 36, non-foundation node 38; Figure 4, Table S1).

The betweenness centrality measure identified three foundation meadows and six non-foundation meadows that were critical for maintaining connectivity (Estrada \& Bodin, 2008) by acting as stepping stones between various different parts of the network
(Figures 2, S2 and S3, Table S1). Stepping stone nodes of the foundation habitat graph were the large meadows of the Whitsunday Islands (node 21), Abbot Point (node 95) and Cleveland Bay (node 92; Figure 4). Stepping stone nodes of the non-foundation habitat graph were the large deep water meadows (nodes 98, 99 and 100) and meadows located near Hinchinbrook Island (nodes 84 and 97) and Cleveland Bay (node 53; Figure 4).The size of meadows influenced betweenness centrality because large meadows have a high outflux of "virtual" propagules and therefore a greater likelihood of encountering other meadows in the 68 dispersal simulations of Grech et al. (2016).

Modularity identified six foundation and four non-foundation discrete communities (Figures 2, 4, S2 and S3). Connectivity in the foundation habitat graph follows a south to north pathway: Repulse Bay (Figure 4e), the Whitsunday Islands (Figure 4e), Edgecumbe Bay-Upstart Bay (Figure 4d), Cleveland Bay and Bowling Green Bay (Figure 4c) and Halifax Bay-Hinchinbrook Island (Figure 4b). The south to north pathway of connectivity is driven by strong southeasterly winds during the peak of the flowering period (Grech et al., 2016). The non-foundation habitat graph exhibits a south to north dispersal pathway along the coast, and also a cross-shelf dispersal pathway (east to west) due to the influence of the three large deep water meadows. The boundaries of the three coastal foundation communities align to the boundaries of the non-foundation communities (i.e. Upstart Bay-Edgecumbe Bay [Figure 4d], Cleveland Bay [Figure 4c] and Halifax Bay-Hinchinbrook Island [Figure 4b]).

The three large deep water meadows form a non-foundation community with a small meadow in Mission Beach (node 91) at the northern boundary of the modelling domain (Figure 4a). Node 91 is weakly connected to other coastal nodes (degree $=7$; Table S1), possibly signalling the northern limit of the central GBRWHA seagrass metapopulation. The four nodes of Repulse Bay are also weakly connected (Figure S2) to the foundation habitat graph relative to other nodes and communities because it faces south-east 


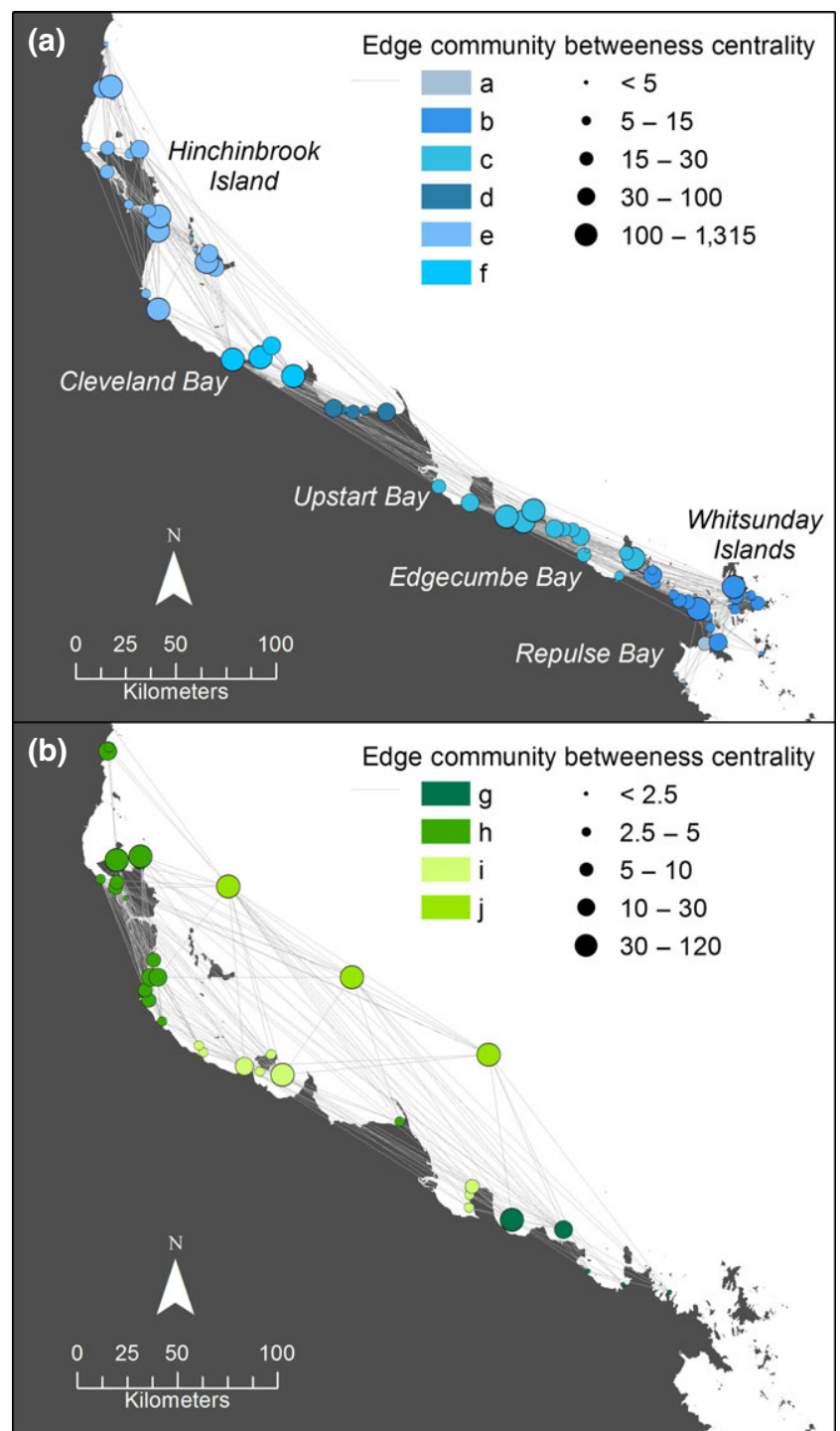

FIGURE 2 Habitat graphs of (a) foundation and (b) non-foundation seagrass meadows in the central Great Barrier Reef World Heritage Area. Each point represents one node (meadow). The size of the node illustrates its betweenness centrality and the colour illustrates its community (see Figure 4). A high betweenness centrality indicates nodes that are critical for maintaining connectivity relative to other meadows by acting as stepping stones between various different parts of the network. Meadows in the same community are more strongly connected with each other than with meadows in other communities. The connections (edges) between nodes are shown in grey, with weaker connections filtered out [Colour figure can be viewed at wileyonlinelibrary.com]

(the predominant wind direction during the peak of the flowering period), possibly signalling the Whitsunday Island community as the southern limit of the central GBRWHA seagrass metapopulation.

The greatest impact to the foundation habitat graph was from the removal of meadows adjacent to the regional city and Port of Townsville, followed by the Port of Abbot Point, Cyclone Debbie, Cyclone Yasi and flooding of the Burdekin River (Figure S1 and Table S2). Cyclone Hamish had no impact on the foundation habitat graph because it occurred over deep water non-foundation meadows only.

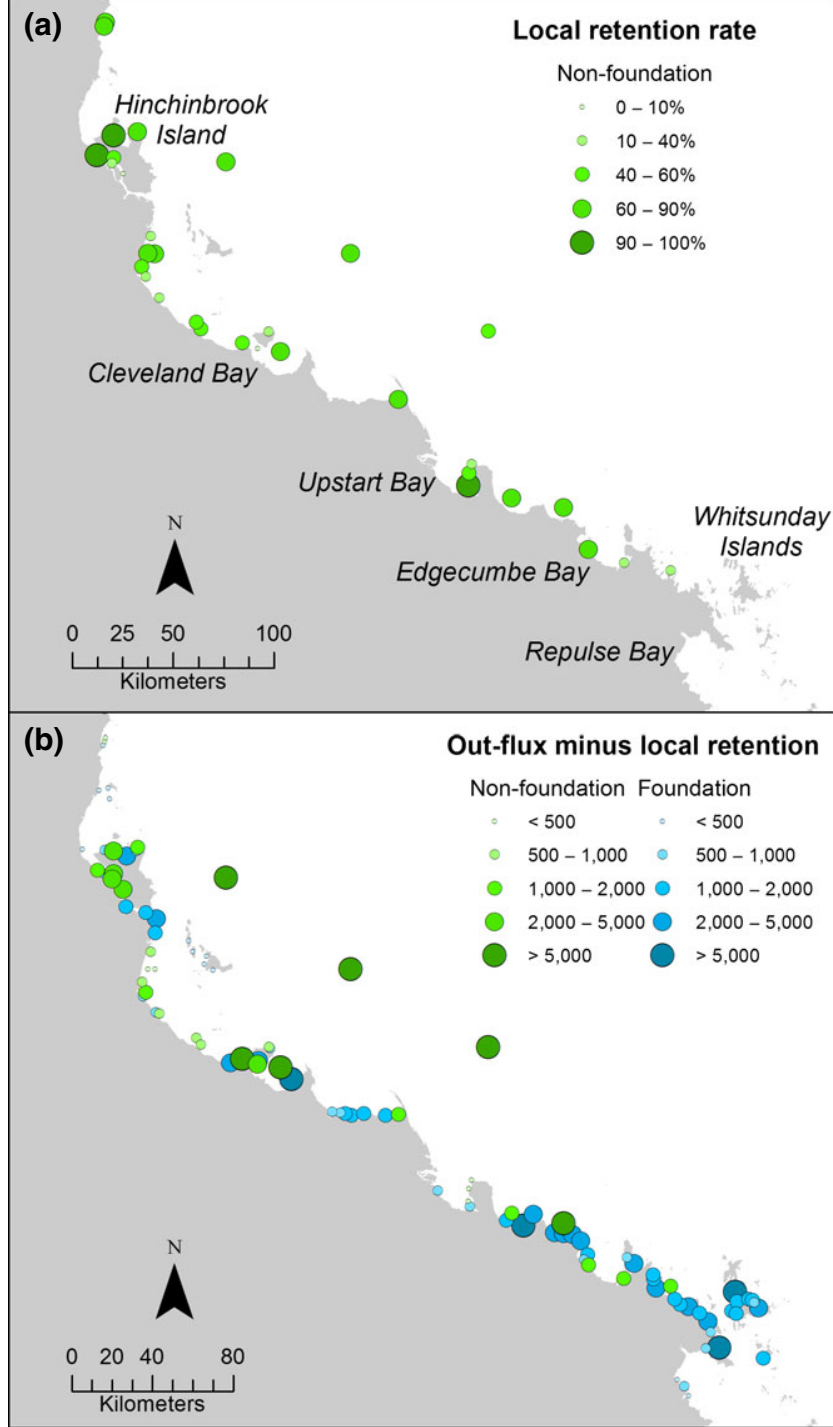

FIGURE 3 (a) Local retention rates of foundation (blue) and non-foundation (green) meadows and (b) outflux (number of "virtual" seagrass propagules released from meadows that settle on themselves or another meadow) minus local retention of foundation (blue) and non-foundation (green) meadows. Each point represents one node (meadow). Meadows with a high local retention rate are more likely to be self-persistent, but are also vulnerable to disturbance events as they are less connected to other meadows. Meadows with a high outflux (minus local retention) are important sources of seagrass propagules relative to other meadows [Colour figure can be viewed at wileyonlinelibrary.com]

The results of the node removal method and dissimilarity matrix did not produce a logical ranking of impact by disturbance events for the non-foundation habitat graph (Table S3), indicating a limitation of the approach for graphs with a small $(<30)$ network order.

The scale of disturbance events required to disconnect the habitat graphs into two or more components was assessed by identifying the furthest cut-node from every meadow in the network. The average distance between every node's furthest cut-node of the foundation habitat graph was $290 \mathrm{~km}$ (STD 102.1) and the non-foundation habitat graph $246 \mathrm{~km}$ (STD 69.5). 


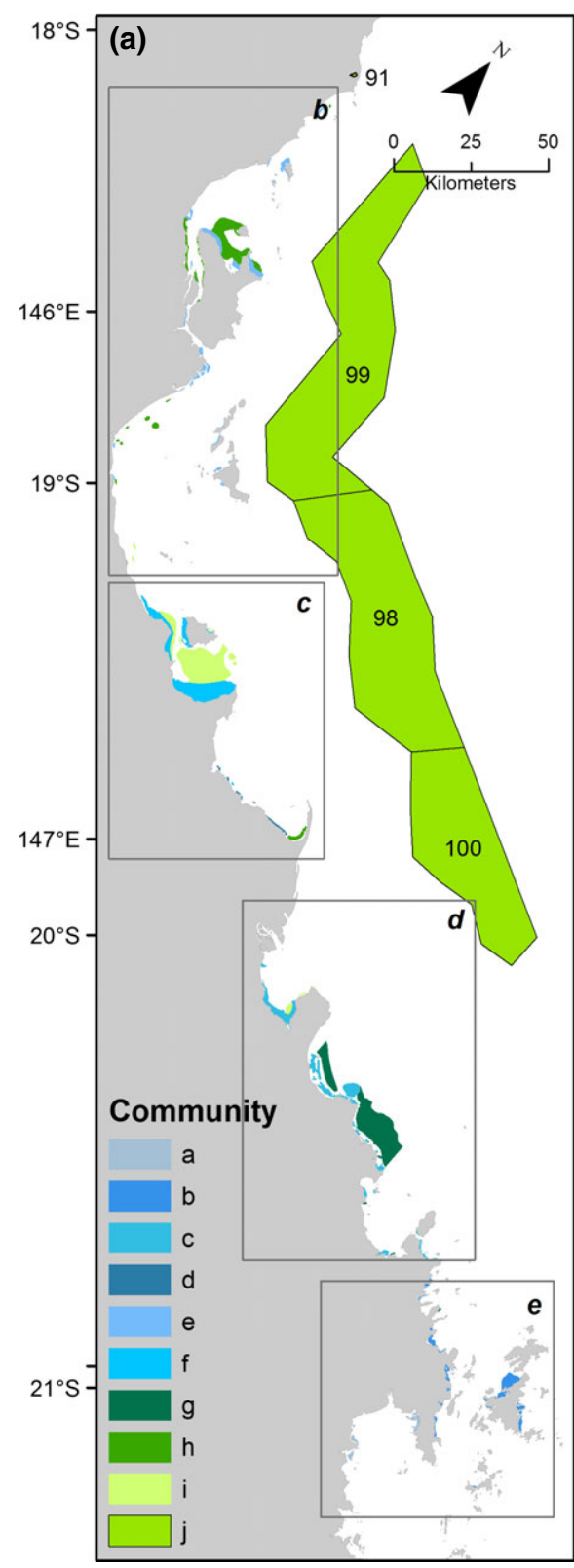

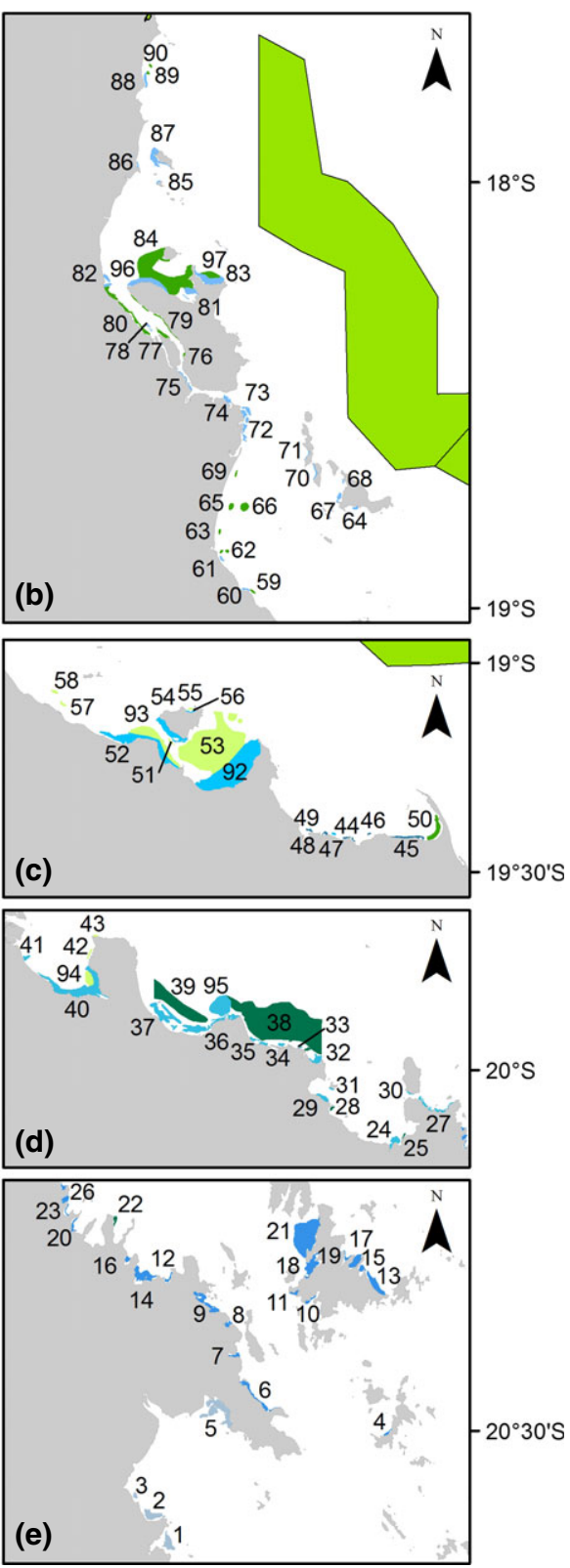

FIGURE 4 Communities of foundation and non-foundation seagrasses in the central Great Barrier Reef World Heritage Area: (a) non-foundation deep water community J; (b) foundation community $E$ and non-foundation community $H$ of the Halifax Bay and Hinchinbrook Island region; (c) foundation community $F$ and non-foundation community I of Cleveland Bay and foundation community $D$ of Bowling Green Bay; (d) foundation community $C$ and non-foundation community $G$ of the Upstart Bay, Abbot Bay and Edgecumbe Bay region; and (e) foundation community $A$ of Repulse Bay and foundation community $B$ of the Whitsunday region [Colour figure can be viewed at wileyonlinelibrary.com]

\section{DISCUSSION}

This study used network analysis and the outputs of a biophysical model to address two questions that are integral to the effective management of coastal habitats: what is the role of connectivity in seagrass replenishment and recovery after disturbance events, and what is the cumulative impact of multiple disturbance events on seagrass connectivity? In our central GBRWHA study area, we found that the seagrass habitat graphs became disconnected into two or more components if the cumulative size of disturbance events was $>245 \mathrm{~km}$. Our analysis also revealed three previously unknown features of seagrasses in the central GBRWHA: (1) seagrass meadows between the Whitsunday Islands and Mission Beach (Figure 1) form a metapopulation within the greater GBRWHA population; (2) deep water non-foundation meadows may function as a stepping stone from the south to the north and are highly connected to coastal meadows; and (3) the central GBRWHA seagrass foundation and non-foundation metapopulations are densely connected and exhibit the properties of small-world networks. This study used a theoretical approach to assess the ecological implications of connectivity, and therefore did not take into account finer scale biological and stochastic processes that may influence propagule production and recruitment in seagrass meadows. We identify locations where empirical studies could be used to assess the production of propagules to verify the conclusions of our study.

We found that the most northerly and southerly nodes in our study area were weakly connected to the foundation and non-foundation habitat graphs (Figures 2, S2 and S3), indicating the existence of a seagrass metapopulation in the central GBRWHA. The most northern meadow in the study area is weakly connected to other coastal meadows and the most southern meadows (Repulse Bay) are south-east facing, limiting their capacity to supply propagules to the 
north. The existence of a seagrass metapopulation in the central GBRWHA has multiple implications for management. For example, disturbance events that impact seagrass meadows at one location potentially have implications for seagrass meadows at other locations within the metapopulation. Maintaining a functional ecosystem, therefore, necessitates considering impacts on seagrass meadows at not only the site of a disturbance event but also at the community (Figure 4) and metapopulation scale in, for example, Environmental Impact Assessments (EIA) for new coastal developments.

It is possible that seagrass metapopulations are spread along the GBRWHA coast at similar scales to the central GBRWHA ( $500 \mathrm{~km})$. Most of the "virtual" propagules released by Grech et al. (2016) remained within the study area and previous modelling of deep water seagrass meadows has suggested the presence of north-south discontinuities in meadow distribution (Coles et al., 2009). Identifying seagrass metapopulations beyond the boundary of the central GBRWHA would require extending the biophysical models to the entire length of the coast $(\sim 2,300 \mathrm{~km})$. Our approach would also be improved by comparing potential functional connectivity of seagrasses with realised connectivity, measured using genetic analyses. However, genetic diversity-based estimates of connectivity reflect the combined outcome of what will potentially be multiple recruitment events over the life of the existing meadow. The potential for dispersal is often predicted to be larger than realised dispersal in marine ecosystems (Burgess et al., 2014; Jahnke et al., 2017). In our study, this could translate to an overprediction of connectivity for meadows that are far apart. However, the longer lived nature of seagrass propagules (viable plant fragments, fruit or spathes) relative to other marine organisms, such as coral larvae (Thomas et al., 2015), supports our predictions of dense habitat graphs with long connections. The reasons for discrepancies between estimates of potential functional connectivity and realised connectivity are postdispersal, presettlement and postsettlement processes (Jahnke et al., 2017). More information on these processes would improve the performance of connectivity studies that rely on biophysical models to measure dispersal and settlement.

The deep water non-foundation meadows exhibited high levels of outflux and betweenness centrality because they are large (total area $>5,800 \mathrm{~km}^{2}$ ), highly connected to coastal meadows and release propagules that have the capacity to disperse over long distances. Grech et al. (2016) recorded particles released from the deep water meadows dispersing $>900 \mathrm{~km}$ to the north. Deep water meadows may function as stepping stones from the south to the north, enabling the sharing of genotypes over long distances. Deep water meadows may also function as an off-shore refuge area for non-foundation seagrasses, assisting in recovery by providing propagules to coastal meadows after major disturbance events. Deep water meadows have previously been shown to be more resilient (higher recovery capacity) than coastal seagrass meadows (Rasheed et al., 2014), enhancing their value as a seagrass refugia. The refugia function of deep water meadows is likely to become more important under climate change because of sea level rise and the predicted increased frequency and energy of the most intense cyclones
(Knutson et al., 2010). However, deep water meadows only produce non-foundation species propagules and have limited effect on the persistence of foundation species. In addition, no evidence or mechanism for connectivity from deep water to coastal seagrass populations of these species has been documented although they are likely to exist.

The foundation and non-foundation habitat graphs exhibited the properties of small-world networks and are therefore resilient to the random loss of nodes because there are many redundant connections (Minor \& Urban, 2007, 2008). Small-world networks are more robust to perturbations than other network architectures and, in biological systems, may reflect an evolutionary advantage (Barabási \& Albert, 1999). However, not all meadows in the habitat graphs were equally important ecologically or for management. Nine meadows in Cleveland Bay, Abbot Point, the Whitsundays, Hinchinbrook Island and deep water had a particularly high outflux and betweenness centrality (Figures 2 and 3, Table S1). This suggests that these nodes should be a high priority for protection and conservation as they perform two important functions: they provide an important source of propagules in the central GBRWHA and serve as stepping stones connecting various parts of the metapopulation. Stepping stones facilitate long-distance dispersal and contribute to species persistence across wide spatial and temporal scales (Saura, Bodin, \& Fortin, 2014). The nine meadows also had a high in-degree, meaning that they are robust to perturbations as many nodes are available to supply them with propagules if they are affected by a disturbance event (Table S1). Empirical studies on seagrass ecology are needed to assess the production and recruitment of propagules and to verify the actual conservation value of the nine meadows.

The outputs of our cumulative impact assessment provided further evidence that seagrasses in the central GBRWHA are robust to multiple disturbance events. We found that the scale of cumulative impact required to disconnect the habitat graphs into two or more components was on average $>245 \mathrm{~km}$, around half the length of the central GBRWHA metapopulation. In context, the very destructive winds of Severe Tropical Cyclone Yasi, one of the largest cyclones in Australia's recent history, covered $\sim 150 \mathrm{~km}$ of coastline. We also found that the locations of disturbance events resulted in differing levels of impact on the foundation habitat graph. Connectivity was effected by impacts occurring in the centre of the metapopulation, near the regional city and Port of Townsville (Cleveland Bay) and the Port of Abbot Point (Figure 1). Foundation meadows in Cleveland Bay are so important to connectivity that their loss is equal to the combined loss of seagrass meadows in the Whitsundays, Abbot Point and Upstart Bay (Figure 1; Table S2). Even though Cyclone Yasi covered the greatest area, it had minimal impact on connectivity as it covered a single, highly connected community (Figure $4 \mathrm{~b}$ ) of relatively low outflux that occurred at the edge of the network (Figure S2). The same approach to assessing cumulative impact did not yield a clear result for the non-foundation habitat graph because its small network order (33) limited the number of nodes that could be removed before the network measures became unstable (Moilanen, 2011). 
Large-scale replanting of seagrasses in response to disturbance events (e.g. Severe Tropical Cyclone Yasi, McKenna et al., 2015) has previously been canvassed by management authorities in the GBRWHA. The evidence base for seagrass restoration is limited by our poor understanding of and ability to provide advice on the alternative action: waiting for natural modes of recovery to occur. Our study informs some of those questions. Supply of propagules for most meadows will not limit replenishment and recovery after disturbance events because meadows in the central GBRWHA are densely connected. The outputs of Tol et al. (2017) further demonstrate that the availability of seagrass propagules in the GBRWHA may assist the natural recovery of seagrass meadows because green turtles and dugong have the ability to move viable seagrass seeds to new locations. Observed slow recovery of seagrass meadows, in excess of 2 years (Preen, Lee Long, \& Coles, 1995), is likely the result of poor postdisturbance environmental conditions such as sediment mobility, changed topography and water quality. Poor environmental health metrics have previously been shown to reduce the likelihood of successful restoration (van Katwijk et al., 2016).

Management approaches to enhance recovery need to include environmental conditions as well as recruitment. Physically restoring seagrass plants are unlikely to be successful until the environmental health of the recipient site has recovered. Once the environment has recovered, we found that planting seagrasses may be unnecessary in most meadows in the study area as propagules, in theory, are readily available and recruitment and recovery could occur naturally. The exceptions to this would be meadows with high local retention but not well connected (e.g. Upstart Bay, Figure 1). There may be other exceptions as the model uses a theoretical production of propagules applied across meadows of the same type. In reality, the production of sexual propagules and fragments may vary both temporally and spatially. Despite these limitations, our approach points to a high degree of connectivity and replenishment potential, and the recent recovery of large-scale losses of seagrasses that occurred in sections of the GBRWHA between 2010 and 2011 would support this (McKenna et al., 2015; Rasheed et al., 2014).

The tropics are faced with a changing global climate, including warming sea temperatures (Hughes et al., 2017) and the increased intensity of tropical storms. The cumulative impact of anthropogenic activities, such as coastal development and poor watershed management, have significantly increased in tropical and coastal regions in the previous decade (Halpern et al., 2015). Losses of seagrass at scales $>245 \mathrm{~km}$ may become frequent. Our study points to the need to understand complex processes, such as connectivity, in order to effectively assess postdisturbance replenishment, recruitment and recovery. Combining the outputs of biophysical models and network analysis offers a powerful framework for understanding the connectivity in marine and coastal ecosystems and identifying important sites that support population persistence. Quantifying the impact of multiple disturbance events on connectivity further informs the likelihood of population persistence under global change. Without this knowledge, management actions, including coastal restoration, may prove unnecessary and be unsuccessful.

\section{ACKNOWLEDGEMENTS}

Funding for this research was provided by Macquarie University, James Cook University, Australian Research Council Centre of Excellence for Coral Reef Studies, the lan Potter Foundation, Sea World Research and Rescue Foundation Inc (SWR/6/15) and WallonieBruxelles International. The authors thank G. Cumming (James Cook University) for advice on the network analysis.

\section{DATA}

Grech, A. (2017). Connectivity of seagrass meadows in the central Great Barrier Reef. James Cook University. https://doi.org/10.4225/ 28/59f7ae655a579

This dataset includes the connectivity matrices of the foundation and non-foundation species habitat graphs and the edge tables for network analysis.

Grech, A. (2017). Network metrics and spatial distribution of seagrass in the central Great Barrier Reef. James Cook University. https://doi.org/10.4225/28/59fbbefa1337c

Spatial (GIS) layer of the 100 seagrass meadows. Attribute table contains information on the node scale network metrics.

\section{ORCID}

Alana Grech iD http://orcid.org/0000-0003-4117-3779

\section{REFERENCES}

Abesamis, R. A., Stockwell, B. L., Bernardo, L. P. C., Villanoy, C. L., \& Russ, G. (2016). Predicting reef fish connectivity from biogeographic patterns and larval dispersal modelling to inform the development of marine reserve networks. Ecological Indicators, 66, 534-544. https://d oi.org/10.1016/j.ecolind.2016.02.032

Allesina, S., \& Pascual, M. (2009). Googling food webs: Can an Eigenvector measure species' importance for coextinctions? PLoS Computational Biology, 5, e1000494. https://doi.org/10.1371/journal.pcbi. 1000494

Almany, G. R., Berumen, M. L., Thorrold, S. R., Planes, S., \& Jones, G. P. (2007). Local replenishment of coral reef populations in a marine reserve. Science, 316(5825), 742-744. https://doi.org/10.1126/science.1140597

Almany, G. R., Connolly, S. R., Heath, D. D., Hogan, J. D., Jones, G. P., McCook, L. J., ... Williamson, D. H. (2009). Connectivity, biodiversity conservation and the design of marine reserve networks for coral reefs. Coral Reefs, 28 (2), 339-351. https://doi.org/10.1007/s00338-009-0484-x

Almany, G. R., Hamilton, R. J., Bode, M., Matawai, M., Potuku, T., SaenzAgudelo, P., ... Jones, G. P. (2013). Dispersal of grouper larvae drives local resource sharing in a coral reef fishery. Current Biology, 23(7), 626-630. https://doi.org/10.1016/j.cub.2013.03.006

Andrello, M., Mouillot, D., Beuvier, J., Albouy, C., Thuiller, W., \& Manel, S. (2013). Low connectivity between Mediterranean marine protected areas: A biophysical modelling approach for the dusky grouper Epinephelus marginatus. PLoS One, 8, e68564. https://doi.org/10.1371/jour nal.pone. 0068564

Barabási, A., \& Albert, R. (1999). Emergence of scaling in random networks. Science, 286(5439), 509-512.

Block, B. A., Jonsen, I. D., Jorgensen, S. J., Winship, A. J., Shaffer, S. A., Bograd, S. J., ... Ganong, J. E. (2011). Tracking apex marine predator 
movements in a dynamic ocean. Nature, 475, 86-90. https://doi.org/ 10.1038/nature10082

Blondel, V. D., Guillaume, J. L., Lambiotte, R., \& Lefebvre, E. (2008). Fast unfolding of communities in large networks. Journal of Statistical Mechanics: Theory and Experiment, 2008, P10008. https://doi.org/10. 1088/1742-5468/2008/10/P10008

Burgess, S. C., Nickols, K. J., Griesemer, C. D., Barnett, L. A., Dedrick, A. G., Satterthwaite, E. V., ... Botsford, L. W. (2014). Beyond connectivity: How empirical methods can quantify population persistence to improve marine protected area design. Ecological Applications, 24(2), 257-270. https://doi.org/10.1890/13-0710.1

Coles, R. G., McKenzie, L. J., De'ath, G., Roelofs, A., \& Lee Long, W. J. (2009). Spatial distribution of deep water seagrass in the inter-reef lagoon of the Great Barrier Reef World Heritage Area. Marine Ecology Progress Series, 392, 57-68. https://doi.org/10.3354/me ps08197

Coles, R. G., McKenzie, L. J., Rasheed, M. A., Mellors, J., Taylor, H., Dew, K., ... Grech, A. (2007). Status and Trends of Seagrass Habitats in the Great Barrier Reef World Heritage Area. Unpublished report to the Marine and Tropical Sciences Research Facility, Reef and Rainforest Research Centre Limited, Cairns, Australia. Retrieved from http:// www.seagrasswatch.org/Info_centre/Publications/113_QDPI_Coles_e t_al_2007_Status_and_Trends.pdf

Coles, R. G., Rasheed, M. A., McKenzie, L. J., Grech, A., York, P. H., Sheaves, M., ... Bryant, C. (2015). The Great Barrier Reef World Heritage Area seagrasses: Managing this iconic Australian ecosystem resource for the future. Estuarine, Coastal and Shelf Science, 153, A1A12. https://doi.org/10.1016/j.ecss.2014.07.020

Cowen, R. K., Paris, C. B., \& Srinivasan, A. (2006). Scaling of connectivity in marine populations. Science, 311(5760), 522-527. https://doi.org/ 10.1126/science.1122039

Cowen, R. K., \& Sponaugle, S. (2009). Larval dispersal and marine population connectivity. Marine Science, 1, 443-466. https://doi.org/10. 1146/annurev.marine.010908.163757

Csardi, G., \& Nepusz, T. (2006). The igraph software package for complex network research. International Journal, Complex Systems, 1695, 1-9. http://www.necsi.edu/events/iccs6/papers/c1602a3c126ba822d0bc 4293371c.pdf

Cumming, G. S., Bodin, O., Ernstson, H., \& Elmqvist, T. (2010). Network analysis in conservation biogeography: Challenges and opportunities. Diversity and Distributions, 16, 414 425. https://doi.org/10.1111/j. 1472-4642.2010.00651.x

D'Aloia, C. C., Bogdanowicz, S. M., Francis, R. K., Majoris, J. E., Harrison, R. G., \& Buston, P. M. (2015). Patterns, causes and consequences of marine larval dispersal. Proceedings of the National Academy of Sciences of the United States of America, 112(45), 13940-13945. https://doi.org/10.1073/pnas.1513754112

Estrada, E., \& Bodin, O. (2008). Using network centrality measures to manage landscape connectivity. Ecological Applications, 18, 1810 1825. https://doi.org/10.1890/07-1419.1

Gonzalez, A., Rayfield, B., \& Lindo, Z. (2011). The disentangled bank: How loss of habitat fragments and disassembles ecological networks. American Journal of Botany, 98(3), 503-516. https://doi.org/10.3732/ ajb.1000424

Grech, A., Chartrand-Miller, K., Erftemeijer, P., Fonseca, M., McKenzie, L., Rasheed, M., ... Coles, R. (2012). A comparison of threats, vulnerabilities and management opportunities in global seagrass bioregions. Environmental Research Letters, 7(2), 024006. https://doi.org/10. 1088/1748-9326/7/2/024006

Grech, A., Wolter, J., Coles, R. G., McKenzie, L. J., Rasheed, M., Thomas, C., ... Hanert, E. (2016). Spatial patterns of seagrass meadow replenishment. Diversity and Distributions, 22, 1150-1162. https://doi.org/ 10.1111/ddi.12479

Halpern, B. S., Frazier, M., Potapenko, J., Casey, K. S., Koenig, K., Longo, C., ... Walbridge, S. (2015). Spatial and temporal changes in cumulative human impacts on the world's ocean. Nature Communications, 6, 7615. https://doi.org/10.1038/ncomms8615

Harrison, H. B., Williamson, D. H., Evans, R. D., Almany, G. R., Thorrold, S. R., Russ, G. R., ... Jones, G. P. (2012). Larval export from marine reserves and the recruitment benefit for fish and fisheries. Current Biology, 22(11), 444446.

Hovey, R. K., Statton, J., Fraser, M. W., Ruiz-Montoya, L., Zavala-Perez, A., Rees, M., ... Kendrick, G. A. (2015). Strategy for assessing impacts in ephemeral tropical seagrasses. Marine Pollution Bulletin, 101(2), 594-599. https://doi.org/10.1016/j.marpolbul.2015.10.054

Hughes, T. P., Bellwood, D. R., Folke, C., Steneck, R. S., \& Wilson, J. (2005). New paradigms for supporting the resilience of marine ecosystems. Trends in Ecology and Evolution, 20, 380-386. https://doi. org/10.1016/j.tree.2005.03.022

Hughes, T. P., Kerry, J. T., Álvarez-Noriega, M., Álvarez-Romero, J. G., Anderson, K. D., Baird, A. H., ... Bridge, T. C. (2017). Global warming and recurrent mass bleaching of corals. Nature, 543(7645), 373-377. https://doi.org/10.1038/nature21707

Jahnke, M., Casagrandi, R., Melià, P., Schiavina, M., Schultz, S. T., Zane, L., \& Procaccini, G. (2017). Potential and realized connectivity of the seagrass Posidonia oceanica and their implication for conservation. Diversity and Distributions, 23(12), 1423-1434. https://doi.org/10. 1111/ddi.12633

van Katwijk, M. M., Thorhaug, A., Marbà, N., Orth, R. J., Duarte, C. M., Kendrick, G. A., ... Cunha, A. (2016). Global analysis of seagrass restoration: The importance of large-scale planting. Journal of Applied Ecology, 53(2), 567-578. https://doi.org/10.1111/1365-2664.12562

Kendrick, G. A., Orth, R. J., Statton, J., Hovey, R., Ruiz-Montoya, L., Lowe, R. J., ... Sinclair, E. A. (2017). Demographic and genetic connectivity: The role and consequences of reproduction, dispersal and recruitment in seagrasses. Biological Reviews, 92(2), 921-938. https://doi. org/10.1111/brv.12261

Kendrick, G. A., Waycott, M., Carruthers, T. J., Cambridge, M. L., Hovey, R., Krauss, S. L., ... Ooi, J. L. (2012). The central role of dispersal in the maintenance and persistence of seagrass populations. BioScience, 62(1), 56-65. https://doi.org/10.1525/bio.2012.62.1.10

Kilminster, K., McMahon, K., Waycott, M., Kendrick, G. A., Scanes, P., McKenzie, L., ... Glasby, T. (2015). Unravelling complexity in seagrass systems for management: Australia as a microcosm. Science of the Total Environment, 534, 97-109. https://doi.org/10.1016/j.scitotenv.2015.04.061

Knutson, T. R., McBride, J. L., Chan, J., Emanuel, K., Holland, G., Landsea, C., ... Sugi, M. (2010). Tropical cyclones and climate change. Nature Geoscience, 3, 157-163. https://doi.org/10.1038/ngeo779

Kool, J., Moilanen, A., \& Treml, E. A. (2013). Population connectivity: Recent advances and new perspectives. Landscape Ecology, 28, 165185. https://doi.org/10.1007/s10980-012-9819-z

Lambrechts, J., Hanert, E., Deleersnijder, E., Bernard, P.-E., Legat, V., Reacle, J.-F., \& Wolanski, E. (2008). A multi-scale model of the hydrodynamics of the whole Great Barrier Reef. Estuarine, Coastal and Shelf Science, 79, 143-151. https://doi.org/10.1016/j.ecss.2008.03.016

Lowe, W. H., \& Allendorf, F. W. (2010). What can genetics tell us about population connectivity? Molecular Ecology, 19(23), 3038-3051. https://doi.org/10.1111/j.1365-294X.2010.04688.x

Magris, R. A., Pressey, R. L., Weeks, R., \& Ban, N. C. (2014). Integrating connectivity and climate change into marine conservation planning. Biological Conservation, 170, 207-221. https://doi.org/10.1016/j.bioc on.2013.12.032

Magris, R. A., Treml, E. A., Pressey, R. L., \& Weeks, R. (2015). Integrating multiple species connectivity and habitat quality into conservation planning for coral reefs. Ecography, 38, 1-16.

McKenna, S., Jarvis, J., Sankey, T., Reason, C., Coles, R., \& Rasheed, M. (2015). Declines of seagrasses in a tropical harbour, North Queensland, Australia, are not the result of a single event. Journal of Biosciences, 40(2), 389-398. https://doi.org/10.1007/s12038-015-95166 
McKenzie, L. J., Yoshida, R. L., Grech, A., \& Coles, R. (2014). Composite of coastal seagrass meadows in Queensland, Australia - November 1984 to June 2010. PANGAEA. Retrieved from https://doi.org/doi.pan gaea.de/10.1594/pangaea.826368

McMahon, K., van Dijk, K., Ruiz-Montoya, L., Kendrick, G. A., Krauss, S. L., Waycott, M., ... Duarte, C. (2014). The movement ecology of seagrasses. Proceedings of the Royal Society B, 281, 20140878. https://d oi.org/10.1098/rspb.2014.0878

Minor, E. S., \& Urban, D. L. (2007). Graph theory as a proxy for spatially explicit population models in conservation planning. Ecological Applications, 17, 1771-1782. https://doi.org/10.1890/06-1073.1

Minor, E. S., \& Urban, D. L. (2008). A graph-theory framework for evaluating landscape connectivity and conservation planning. Conservation Biology, 22(2), 297-307. https://doi.org/10.1111/j.1523-1739.2007. 00871.x

Moilanen, A. (2011). On the limitations of graph-theoretic connectivity in spatial ecology and conservation. Journal of Applied Ecology, 48(6), 1543-1547. https://doi.org/10.1111/j.1365-2664.2011.02062.x

Moore, C., Grewar, J., \& Cumming, G. (2016). Quantifying network resilience: Comparison before and after a major perturbation shows strengths and limitations of network metrics. Journal of Applied Ecology, 53, 636-645. https://doi.org/10.1111/1365-2664.12486

Orth, R. J., Carruthers, T. J., Dennison, W. C., Duarte, C. M., Fourqurean, J. W., Heck, K. L., ... Short, F. T. (2006). A global crisis for seagrass ecosystems. BioScience, 56(12), 987-996. https://doi.org/10.1641/ 0006-3568(2006)56[987:AGCFSE]2.0.CO;2

Planes, S., Jones, G. P., \& Thorrold, S. R. (2009). Larval dispersal connects fish populations in a network of marine protected areas. Proceedings of the National Academy of Sciences of the United States of America, 106(14), 5693-5697. https://doi.org/10.1073/pnas.0808007106

Preen, A., Lee Long, W. J., \& Coles, R. G. (1995). Flood and cyclone related loss, and partial recovery, of more than $1000 \mathrm{~km}^{2}$ of seagrass in Hervey Bay, Queensland. Australia. Aquatic Botany, 52 (1-2), 3-17.

Rasheed, M. A. (1999). Recovery of experimentally created gaps within a tropical Zostera capricorni (Aschers.) seagrass meadow, Queensland Australia. Journal of Experimental Marine Biology and Ecology, 235(2), 183-200. https://doi.org/10.1016/S0022-0981(98)00158-0

Rasheed, M. A. (2004). Recovery and succession in a multi-species tropical seagrass meadow following experimental disturbance: The role of sexual and asexual reproduction. Journal of Experimental Marine Biology and Ecology., 310(1), 13-45. https://doi.org/10.1016/j.jembe. 2004.03.022

Rasheed, M. A., McKenna, S. A., Carter, A. B., \& Coles, R. G. (2014). Contrasting recovery of shallow and deep water seagrass communities following climate associated losses in tropical north Queensland, Australia. Marine Pollution Bulletin, 83, 491-499. https://doi.org/10.1016/ j.marpolbul.2014.02.013

Rayfield, B., Fortin, M. J., \& Fall, A. (2011). Connectivity for conservation: A framework to classify network measures. Ecology, 92(4), 847-858. https://doi.org/10.1890/09-2190.1

Ruiz-Montoya, L., Lowe, R. J., \& Kendrick, G. A. (2015). Contemporary connectivity is sustained by wind- and current-driven seed dispersal among seagrass meadows. Movement Ecology, 3, 9. https://doi.org/ 10.1186/s40462-015-0034-9

Saunders, M. I., Brown, C. J., Foley, M. M., Febria, C. M., Albright, R., Mehling, M. G., ... Burfeind, D. D. (2016). Human impacts on connectivity in marine and freshwater ecosystems assessed using graph theory: A review. Marine and Freshwater Research, 67, 277-290.

Saura, S., Bodin, O., \& Fortin, M. J. (2014). Stepping stones are crucial for species' long-distance dispersal and range expansion through habitat networks. Journal of Applied Ecology, 51(1), 171-182. https://doi.org/10.1111/1365-2664.12179

Steneck, R. S., Paris, C. B., Arnold, S. N., Ablan-Lagman, M. C., Alcala, A. C., Butler, M. J., ... Sale, P. F. (2009). Thinking and managing outside the box: Coalescing connectivity networks to build region-wide resilience in coral reef ecosystems. Coral Reefs, 28(2), 367-378. https://d oi.org/10.1007/s00338-009-0470-3

Thomas, C. J., Bridge, T. C. L., Figueiredo, J., Deleersnijder, E., \& Hanert, E. (2015). Connectivity between submerged and near-sea-surface coral reefs: Can submerged reef populations act as refuges? Diversity and Distributions, 21(10), 1254-1266. https://doi.org/10.1111/ddi.12360

Thomas, C. J., Lambrechts, J., Wolanski, E., Traag, V. A., Blondel, V. D., Deleersnijder, E., \& Hanert, E. (2014). Numerical modelling and graph theory tools to study ecological connectivity in the Great Barrier Reef. Ecological Modelling, 272, 160-174. https://doi.org/10.1016/j.ec olmodel.2013.10.002

Tol, S., Jarvis, J., York, P., Grech, A., Congdon, B., \& Coles, R. (2017). Long distance biotic dispersal of tropical seagrass seeds by marine mega-herbivores. Scientific Reports, 7, 1-8.

Treml, E. A., \& Halpin, P. A. (2012). Marine population connectivity identifies ecological neighbours for conservation planning in the coral triangle. Conservation Letters, 5, 441-449. https://doi.org/10.1111/j. 1755-263X.2012.00260.x

Treml, E. A., Halpin, P. A., Urban, D. L., \& Pratson, L. (2008). Modeling population connectivity by ocean currents: A graph-theoretic approach for marine conservation. Landscape Ecology, 23, 19-36. https://doi.org/10.1007/s10980-007-9138-y

Unsworth, R. K., van Keulen, M., \& Coles, R. G. (2014). Seagrass meadows in a globally changing environment. Marine Pollution Bulletin, 83 (2), 383-386. https://doi.org/10.1016/j.marpolbul.2014.02.026

Urban, D. L., \& Keitt, T. (2001). Landscape connectivity: A graph-theoretic perspective. Ecology, 82(5), 1205-1218. https://doi.org/10.1890/ 0012-9658(2001)082[1205:LCAGTP]2.0.CO;2

Urban, D. L., Minor, E. S., Treml, E. A., \& Schick, R. S. (2009). Graph models of habitat mosaics. Ecology Letters, 12(3), 260-273. https://doi. org/10.1111/j.1461-0248.2008.01271.x

Waycott, M., Duarte, C. M., Carruthers, T. J., Orth, R. J., Dennison, W. C., Olyarnik, S., ... Kendrick, G. A. (2009). Accelerating loss of seagrasses across the globe threatens coastal ecosystems. Proceedings of the National Academy of Sciences of the United States of America, 106 (30), 12377-12381. https://doi.org/10.1073/pnas.0905620106

York, P. H., Carter, A. B., Chartrand, K., Sankey, T., Wells, L., \& Rasheed, M. A. (2015). Dynamics of a deep-water seagrass population on the Great Barrier Reef: Annual occurrence and response to a major dredging program. Scientific Reports, 5, 13167. https://doi.org/10. 1038/srep13167

York, P. H., Smith, T. M., Coles, R. G., McKenna, S. A., Connolly, R. M., Irving, A. D., ... Sullivan, B. K. (2017). Identifying knowledge gaps in seagrass research and management: An Australian perspective. Marine Environmental Research, 127, 163-172. https://doi.org/10.1016/ j.marenvres.2016.06.006

\section{SUPPORTING INFORMATION}

Additional Supporting Information may be found online in the supporting information tab for this article.

How to cite this article: Grech A, Hanert E, McKenzie L, et al. Predicting the cumulative effect of multiple disturbances on seagrass connectivity. Glob Change Biol. 2018;24:3093-3104. https://doi.org/10.1111/gcb.14127 